\title{
Innovation Ecosystems as Structures for Value Co-Creation
}

Sanna Ketonen-Oksi and Katri Valkokari

\author{
' The most important inventions and the most successful") \\ people are driven by collaboration. Collective inventions, \\ by definition, require tolerance and diversity, and they \\ cannot be cut from the same cloth.
}

Francisco Varela (1946-2001)

Biologist, philosopher, and neuroscientist

\begin{abstract}
Despite the many recent discussions on "innovation ecosystems" as well as on open innovation or other co-innovation models, a more in-depth understanding of the multi-actor processes of value co-creation remains rather scarce. Hence, in this case study, we provide significant novel insight about innovation ecosystems as structures enabling multi-actor value co-creation in real-life innovation ecosystems. Based on our empirical findings, we identified two key principles: 1) in order to encourage the active participation of ecosystem actors in the value co-creation process, efforts must be made to ensure a clear vision and a shared value base on which the ecosystem activities can be built and 2) facilitation is needed to support the ecosystem actors to make new connections and to share their knowledge and resources in concrete ways. Most importantly, the more diversity there is among the ecosystem actors, the greater the support for innovativeness within the value co-creation process.
\end{abstract}

\section{Introduction}

In recent years, a more dynamic view of business and innovation has emerged (Whalen \& Akaka, 2016). Instead of conceptualizing innovation as a firm-centric activity, the emphasis has now shifted towards both the service providers' and the customers' abilities to engage themselves in large, external networks for value creation (Romero \& Molina, 2011). However, with a limited focus of analysis on interactions and value transactions, the understanding of innovation as a process that consists of multiple different actors and practices (Helkkula et al., 2018; Kartemo et al., 2018;) remains rather poor (Barile et al., 2016; Järvi \& Kortelainen, 2017; Suominen et al., 2016).

Indeed, given the growing dynamism and complexity of modern business environments, companies are becoming more and more dependent on their external networks crossing many disciplines and industries. In order to maintain their competitiveness, network-specific innovation capabilities have become a lifeline for many companies (Valkokari et al., 2016). When building up these dynamic and more futures-oriented innovation capabilities, companies may well even double their economic growth (Rohrbeck et al., 2018). By thus highlighting the role of collaborative organizational structure and culture (Aarikka-Stenroos \& Ritala, 2018; Smorodinskaya et al., 2017), the literature related to innovation management has been lately undergoing a significant transformation towards a more networked and systemic nature of value creation (Järvi \& Kortelainen, 2017; Lee et al., 2012; Vargo \& Lusch, 2016). This includes the increased focus on more collaborative practices of knowledge creation.

However, despite many years of active discussions on open innovation or other co-innovation models (Lee et al., 2012), understanding of the (inter)relationships between the different actors involved in the actual value co-creation processes has remained rather scarce (Barile et al., 2016; Järvi \& Kortelainen, 2017). Besides the arising interest on remodelling the former solutionsbased innovation policies and practices, more real-life examples are needed to challenge the theoretical approaches to and exuberantly positive discussion on 


\title{
Innovation Ecosystems as Structures for Value Co-Creation
}

\author{
Sanna Ketonen-Oksi and Katri Valkokari
}

value co-creation (Clarysse et al., 2014; Lintula et al., 2017). That is, greater effort and coordination are needed to engage researchers in different fields of science to empirically test and re-conceptualize the fit between the theoretical foundations and current discussions regarding value co-creation.

So far, academic studies have been primarily concerned with the strategic positioning of firms within ecosystems. In doing so, they have referred to ecosystems according to their various contextually or functionally changing roles (Akaka et al., 2017; Autio \& Thomas, 2014; Spigel, 2017). Despite Adner's (2016) earlier work, calling for a structuralist approach to conceptualizing the ecosystem construct, the current understanding about the structures and practices supporting value cocreation in innovation ecosystems is still very limited. In particular, studies on value co-creation as a process, consisting of a high number of value transactions between the various loosely-coupled ecosystem actors, are practically non-existent. Therefore, in this study, we use a two-part model approach for value co-creation (Galbrun \& Kijima, 2009; Kijima \& Arai, 2016) to: i) understand how ecosystems could be developed as structures for value co-creation and ii) identify the key practices shaping these structures.

First, we provide a brief overview of the key concepts used in this study, as well as the chosen research approach and data collection method. Then, based on two empirical case studies, we identify and discuss the key prerequisites to support the ecosystem actors' abilities to first unfold and then either maintain or remodel the different structures and practices of value co-creation.

\section{Key Concepts}

\section{Innovation ecosystems: The new dynamics of}

collaboration

Ever since the concept of business ecosystems (Moore, 1993) was first introduced, different concepts of ecosystems have emerged, disrupting the traditional boundaries between organizations and industry sectors. As for now, they all tend to encourage companies to widen their views and practices related to industry-specific partnerships (Aarikka-Stenroos \& Ritala, 2018; Adner, 2016). Given that the concept of innovation ecosystems has been previously tied up around the creation of growth, local collaboration, and innovative startups in so-called knowledge hubs (Engel \& Del-Palacio, 2011), a broader view of innovation ecosystems has been introduced.
Innovation ecosystems are "dynamic and co-productive spaces for research, development, and innovation (R\&D\&I) activities that are characterized by a high level of interdependence and co-evolution of value between the industry and research-based ecosystem actors" (Adner \& Kapoor, 2010; Autio \& Thomas, 2014; according to Schroth \& Häußermann, 2018, p. 4). In other words, innovation ecosystems, just as entrepreneurial or knowledge ecosystems, are strongly connected with their ability to explore and adopt new knowledge (Valkokari, 2015). However, the motivations for knowledge sharing are different depending on the type of the ecosystem. Where innovation ecosystems are focused on interdisciplinary and cross-sectoral collaboration which results in new competencies and resources (Schroth \& Häußermann, 2018), the entrepreneurial ecosystems are more directed towards coordinating and fostering social networks within particular geographical contexts (Stam \& Spiegel, 2016). And, knowledge ecosystems are organized around a joint knowledge search on a particular context of study (Järvi \& Almpanopoulou, 2018).

\section{Value co-creation: A focus on innovation as a continuous process}

Given the arising need for a more dynamic and practice-oriented view on innovation, the importance of a continuous interplay between the various ecosystem actors with many several overlapping purposes and different views on ecosystems has been strongly emphasized (Meynhardt et al., 2016; Parker et al., 2016). That is, there has been a growing interest in social cognition and connectivity (Knyazev et al., 2018) that underlies the socially constructed meanings (Adler, 2015) and the highly interactive, even symbiotic logic of value co-creation (Dattée et al., 2018; Meynhardt et al., 2016; Smorodinskaya et al., 2017). Instead of simply referring to innovation as the successful implementation of creative ideas within an organization, more attention has been given to value co-creation as a collaborative process (Edvardsson et al., 2011; Rajala et al., 2016).

For a long time, the term "value" was only used when referring to value that was created through the manufacture and distribution of tangible goods (Prahalad \& Ramaswamy, 2004; Vargo et al., 2008). However, in recent years, a growing tendency towards a more systemic view on value co-creation has emerged. By embracing the concepts of value-in-use and value-incontext, rather than the concepts of value-in-exchange and embedded-value, the supplier-driven value chains have now been replaced with value networks that gather all stakeholders (Vargo \& Lusch, 2008). According to 


\section{Innovation Ecosystems as Structures for Value Co-Creation}

\section{Sanna Ketonen-Oksi and Katri Valkokari}

this increasingly accepted, more systemic, and transdisciplinary view on value co-creation, value co-creation is defined as "the joint, collaborative, concurrent, peerlike process of producing new value, both materially and symbolically" (Calvagno \& Dalli, 2014).

Hence, by shedding light on the interdependencies between the repetitive sequences of cooperation, conflict, and compromise (Pellikka \& Ali-Vehmas, 2016), it is clear that the alignment of value is not always possible or even desirable (Pera et al., 2016). In other words, consisting of both intentional and emergent actions, contributions to value co-creation may be either positive or negative (Lintula et al., 2017) - or simply neutral. As a result, it seems that many of the existing theoretical frameworks and models now fail to provide suitable tools for adapting this more dynamic view on value co-creation in practice (Koskela-Huotari et al., 2016). For this reason, in this study, the understanding of both value co-creation and value co-destruction are included in the exploration and analysis of the value cocreation process.

\section{Research Approach and Data}

Considering innovation as a major challenge to practitioners in both the private and public sectors, in business and in research, a more systemic view is needed of innovation as a complex process of interactions between a dynamic configuration of people, organizations, and knowledge (Kijima, 2015). That is, whereas Adner (2016) has raised a discussion about ecosystemsas-structures, viewing ecosystems as configurations of activities that are defined by a shared value proposition, our aim is to explore innovation ecosystems as systems that focus on generating new knowledge. With this in mind, we see innovation ecosystems as more open and loosely-coupled systems that allow the ecosystem actors to use the acquired knowledge in their own particular ways, for example, in their firm-specific business ecosystems.

Hence, in order to examine the development of these desired, more dynamic, and futures-oriented innovation capabilities in the real-life ecosystems, a two-part model on value co-creation is applied (Kijima \& Arai, 2016) as the framework of analysis. To do so, we refer to the service science's view on innovation as something that is always embedded in the value co-creation structures (Lusch \& Nambisan, 2015). In this study, innovation is to be considered as the outcome of a gradually evolving process that unfolds the existing, both explicit and implicit perceptions of value co-creation.

\section{A two-part model for value co-creation}

First introduced in 2009, the two-part model for value co-creation consists of two separate yet partly overlapping concepts (see Figure 1): platforms and ecosystems. On the one hand, the concept of a platform refers to the first part, where different actors meet one another and become interested in value co-creation. On the other hand, the ecosystem concept refers to the second part, where the actual value co-creation takes place in four major phases of interaction (Kijima \& Arai, 2016). By thus seeing platforms as venues where the ecosystem actors can connect with one another (i.e., as venues for

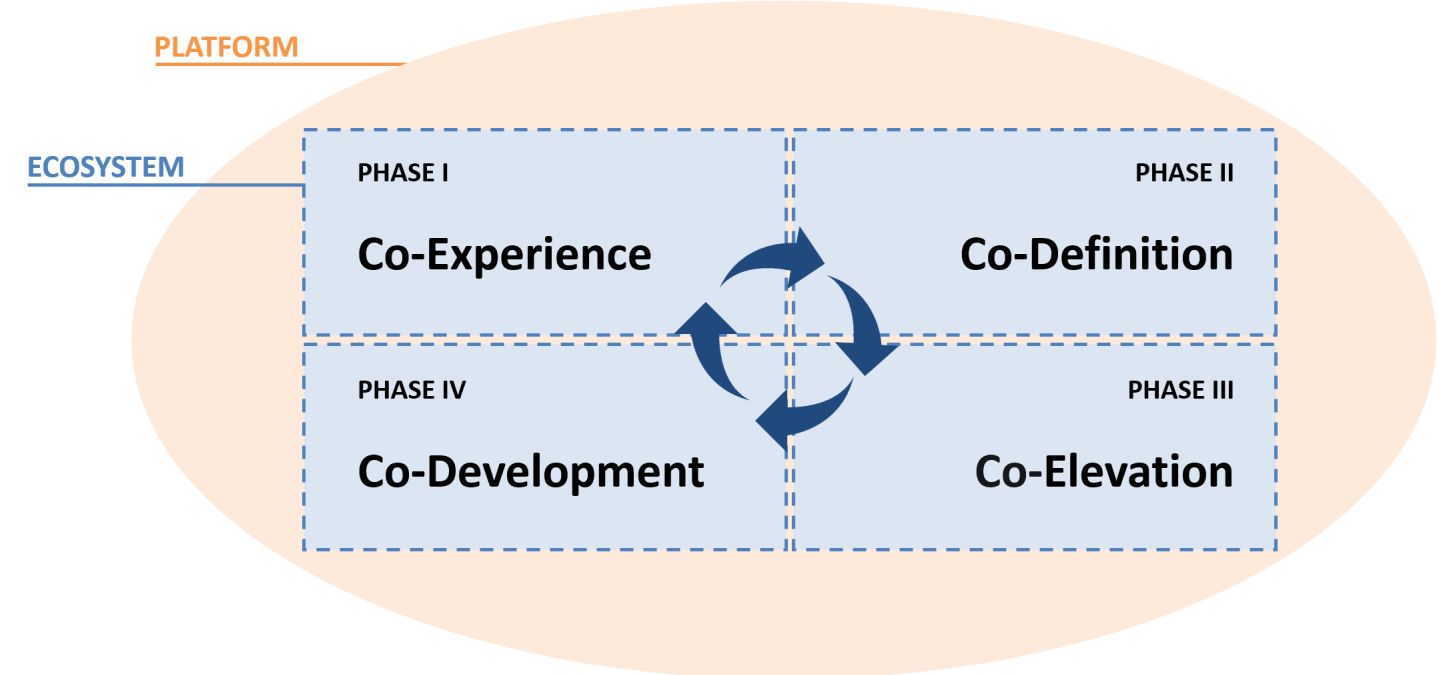

Figure 1. The process of value co-creation (see Galbrun \& Kijima, 2009) 


\title{
Innovation Ecosystems as Structures for Value Co-Creation
}

\author{
Sanna Ketonen-Oksi and Katri Valkokari
}

innovation), the focus on platforms remains in facilitating and orchestrating actions that may eventually lead to value co-creation or co-destruction. Therefore, it is important to invite as many and as wide a variety of actors as possible to join the platforms. Then, with the support of the actual innovation process, consisting of four phases - co-experience, co-definition, co-evolution, and co-development - the systemic and progressive nature of the value co-creation process can be actualized.

In practice, the value co-creation process starts once the ecosystem actors come together in terms of mutually shared interests in innovation. During the first phase (co-experience) the ecosystem actors become aware of their needs and expectations, and gradually start to mirror them against the needs and expectations of other ecosystem actors representing a number of different individuals and organizations. Then, during the second phase (co-definition), the actors come across with each other's capabilities to share their internal models and perceptions of value co-creation. In the third phase (co-evolution), the focus finally turns to actual value propositions, strengthened by an active communication between the ecosystem actors. Last is at the fourth phase (co-development), where the concrete value co-creation - or co-destruction - is actualized and evaluated (Galbrun \& Kijima, 2009; Kijima et al., 2014).

The overall purpose of these four phases is to emphasize the active, creative, and social nature of the value cocreation process. They also create a structure that supports the ways in which the value co-creating actors engage in the process of continuous interaction through knowledge creation and exchange. Considering the depth of collaboration during the process, objectives and goals must be clearly expressed and discussed. This process requires effort and commitment from all the value co-creators. By interacting with one another, the different actors learn about each other's expectations and needs, aiming at a shared internal model (i.e., shared practices and principles that feed the process). During these four phases, multiple approaches to addressing the mental and physical aspects of human beings are curated and empowered (Galbrun \& Kijima, 2009; Kijima \& Arai, 2016).

\section{Case selection}

The case selection of two different ecosystems was made in line with guidelines for case research (Eisenhardt, 1989). Based on the researchers' access to the underlying processes of value co-creation in the two different ecosystems, the selected cases were both comparable and complementary to one another. That is, both ecosystems were built around a physical platform as the core of the ecosystem, with a different number and variety of ecosystem actors, but they represented different fields of industry. In addition, both ecosystems were still under construction. Hence, special attention was given to maximizing the multidimensionality of the research approach and data collection, thus resulting in rich learning and exploration through the selected cases.

The first ecosystem (case A) was built around a multitude of ecosystem actors that aim at developing a leading centre for the actors in a sustainable bio-economy, both in Finland and globally. In doing so, it aims to create an open, dynamic, multi-actor ecosystem for business, research, and education within the field of cleantech innovation. Originally, the initiative for this ecosystem development was made by a large research institute who then decided to move its research laboratories to this hotspot. Eventually, the research laboratories formed the core of the innovation ecosystem.

The second ecosystem (case B) was purposefully designed to encourage and support productive collaboration between a technology university and its many stakeholder organizations. Situated at the centre of a university campus and co-managed by the owner of the ecosystem properties and the university, it offers a broad range of services and multipurpose facilities for learning and innovation.

\section{Data collection}

Based on a qualitative, multiple-case-study approach, the empirical data of this study consists of both interviews and focus group observations. All data was first collected and then analyzed by two independent researchers (i.e., the authors of this article). The informants (i.e., interviewees and focus group members) included a variety of ecosystem actors: (senior) corporate executives, managers, researchers, and university staff - a variety of people involved in the ecosystem development, management, and utilization. Altogether, over 40 people were interviewed in the studied ecosystems. The data sources are summarized in Table 1.

The collected data differs in form: the case A data consists of several focus group meetings where ecosystem actors are building shared understanding, whereas the case B data consists mostly of interview data. This is because the case A data focus more on the composing 


\title{
Innovation Ecosystems as Structures for Value Co-Creation
}

\author{
Sanna Ketonen-Oksi and Katri Valkokari
}

Table 1. Data sources

\begin{tabular}{lll}
\hline Case & Interviews & Focus Groups \\
\hline $\mathrm{A}$ & Interviews 13 (representatives of 7 organizations) & 12 focus group meetings $(01 / 2017-11 / 2018)$ \\
\hline $\mathrm{B}$ & Interviews 22 (representatives of 10 organizations) & 1 focus group in August 2016, and 1 focus group in March 2018 \\
\hline
\end{tabular}

phase of the ecosystem, while case B complements it with data on an already exiting interaction platform and the ecosystem around it. In reality, the value cocreation process is iterative, and the four phases of value co-creation are often overlapping one another. In order to place each of the identified structures and practices according to the here presented four phases, they are aligned with the specific focus of individual phases (such as raising awareness at the co-experience phase).

\section{Case Findings}

Platforms as the initial settings for value co-creation In both cases, a physical place formed the core of the value co-creation (Table 2). In case $B$, one of the stakeholders stated that being present at a specific location for value co-creation was considered as an important benefit: "This place represents a no man's land, easily accessible to all kinds of actors." The importance of the diversity of actors was also highlighted by the co-managers: "It's strategically important that the campus welcomes different actors to work in the same premises."

In case A, not all actors were present at the same location and the research facilities were not open to all. Many parties were interested, but the development was strongly led by the research institute and the focus was on research infrastructure. Many separate subcomponents arose out of the common agenda during the value co-creation process, but the physical location could also hinder ecosystem building. It was important that the actors identified themselves with the ecosystem and were committed to joint collaboration and to opening up their own interests.

\section{Understanding the process of value co-creation}

In case $\mathrm{A}$, the aim was to create a close development network with a common technology roadmap, referring to the "sustainability of society and growth of an industry sector". In case B, the ecosystem development started by creating a space where people can meet. At this first phase of value co-creation (see Table 3), the role of facilitation was seen as very important. As stated by the facilitator working in case B, "the role of facilitator is to be enthusiastic, to make people enthusiastic and to innovate". Similarly, in case A, the facilitator's role was in engaging different actors in value co-creation. This happened through formal or informal discussions, and by presenting the research facilities to hundreds of visitors during the year.

In both ecosystems the physical facilities were recognized as a valuable showcase of innovation activity and opportunity creation, or, as one of the university actors in case B expressed: "to enhance different forms of cross- and transdisciplinary collaboration". Again, one of the stakeholders, a city representative actively involved in the case A development said that: "These facilities and the research done here attract global forerunners to take part in networks of innovation. It's easy to invite new actors - this is an excellent example of our strengths in this technology sector."

In phase II (see Table 4), the role of facilitation was still rather important, as highlighted by the participants in case B: "If the aim is to really mix people and ideas, more support is needed to activate the co-creation process" and "Allocating more time for the platform activities would certainly be beneficial." As pointed out by the ecosystem developers from case B, "It takes time before

Table 2. Observations related to the core value of platform orchestration

\section{Case Core Value}

A Platform integrating different research facilities, enabling knowledge, and resource sharing

B Platform enabling collaboration between diverse actors with different backgrounds, orientations, and interests 


\section{Innovation Ecosystems as Structures for Value Co-Creation}

Sanna Ketonen-Oksi and Katri Valkokari

Table 3. Observations related to the co-creation processes: Phase I

\section{Case Phase I: Co-Experience}

A - An ecosystem facilitator, employed by the research institute, boosted the evolution.

- The shared vision was rather generic.

- A jointly created ecosystem brand supported stronger commitment by the participating city.

- Regular meetings supported networking and updates between the actors.

B - It was well acknowledged that the ecosystems' learning process takes time.

- The role of interactions was highly appreciated.

- Diversity was regarded as an asset by some ecosystem actors, but not all.

Table 4. Observations related to the co-creation processes: Phase II

\section{Case Phase II: Co-Definition}

A - New connections and encounters were constantly being created, bringing together actors from different subassemblies (e.g., educational institutes).

- Two other research institutes and one company also decided to locate some of their research facilities and personnel in the same building.

- More diversity was needed, and this issue was being actively worked on.

B - The role of facilitation was essential in enhancing value co-creation. The phase of co-definition was exponentially growing due to various meetings and events.

- Many of the ecosystem actors were more or less observing the platform instead of actively participating.

- Co-creation was understood in a rather generic way.

- Some conflicts manifested as differences between the ecosystem actors' expectations, and their ability to act upon the shared visions varies greatly.

- The focus of discussions were largely related to sharing one's own knowledge and understanding of issues that attract interest.

people get familiar with new concepts". Furthermore, as pointed out by the facilitator of case A, the ecosystem facilitator should not be tightly connected to the content creation, but "to be an enabler and connector and to support the substance experts so that they can focus on their research".

While the role of facilitator was highlighted during the first phases of value co-creation, in this co-elevation phase (see Table 5), the facilitator should take a back seat. This results in shared responsibilities and fosters multiple development perspectives. In addition, in both of the studied ecosystems, there was a lot of talk about and much interest in value co-creation, but the abilities to practice it varied considerably. However, if the objectives are not clear and efforts are not made to learn by doing, that is, if the discussions do not lead to a shared knowledge and understanding of the expected outputs, ecosystems may not evolve in the long run. Thus, in case A, the benefits of shared research infrastructures represented an important and concrete value for the ecosystem, as described by a research organization representative: "these shared facilities enable us to follow and benefit from the research progress of our partners". 


\section{Innovation Ecosystems as Structures for Value Co-Creation}

Sanna Ketonen-Oksi and Katri Valkokari

Table 5. Observations related to the co-creation processes: Phase III

\section{Case Phase III: Co-Elevation}

A - Ecosystem actors were more active in development and in suggesting new connections, initiatives, and partners (both national and international).

- Investigations were made to locate new actors and their activities in the same physical location.

- Ecosystem facilitation was shared among participants. A new leading actor emerged.

B - Co-creation seemed not to turn into action but remains a topic of discussion.

- Things were mainly run from a company-specific viewpoint.

- Co-creation was first limited to some of the leading ecosystem actors but grew in active content or goal-specific networks.

- Changes in the working cultures are slow; they did not merge.

- Sharing was first limited due to trust and competitiveness issues, but more recently, a lot of product development and research has taken place within the ecosystem.

- The ecosystem sheltered individual institutions and networks.

- Understanding of the ecosystem started to develop in more profound ways.

Given the low maturity of case A, the actors have not yet had enough time to develop the goals and objectives needed to reach the co-development phase (see Table 6). As the four-phase model of value co-creation initially suggests, it seems to take a long time for some ecosystem actors to integrate into the value co-creation processes. As revealed in case B, it is only after several years that the shared vision of ecosystem functionalities reaches a phase where the unusual diversity of the actors becomes an asset rather than a limitation for a shared vision. Regarding the platform-specific innova- tion hub, limited to only some ecosystem actors, the vision is clear, and the role of the facilitation has developed accordingly.

Having observed the ecosystem actors' different perspectives and understanding of the concepts of platform and ecosystem, as well as how they operated according to alternative innovation management "theories of practice", significant impacts were detected on their mindsets and - eventually - on their value co-creation practices. The need for radical change was largely

Table 6. Observations related to the co-creation processes: Phase IV

\section{Case Phase IV: Co-Development}

A - There was a lack of a detailed roadmap for the entire ecosystem, with some more focused roadmaps for the subassemblies.

- There was no common assessment framework (i.e., the clear and measurable objectives were missing).

B - Co-creation mainly took place at the platform-specific innovation hub.

- An increasing number of actors were joining the activities on a continuous basis.

- Some ecosystem actors have a very limited, linear and mechanical view on innovation; some members considered ecosystems to be fully functioning only when systemic thinking was applied.

- The use of a variety of different communication channels increased.

- More disruption was needed to unfold the dominant practices of collaboration. 


\section{Innovation Ecosystems as Structures for Value Co-Creation}

\section{Sanna Ketonen-Oksi and Katri Valkokari}

acknowledged. Yet, due to uncertainties about the impacts of value co-creation on future business models and the roles within the future ecosystems, the business actors' willingness to engage in open discussion and collaboration were clearly diminished.

\section{The development of value co-creation practices}

The importance of understanding the differences between the four phases of value co-creation was highlighted in both case studies. Figures 2 and 3 summarize the thus identified value co-creation practices.

\section{Conclusions}

As the existing studies still tend to only focus on firmspecific viewpoints (Adner \& Kapoor, 2010; Akaka et al., 2017) and certain types of ecosystems (Pellikka \& AliVehmas, 2016), the aim of this study was to shed light on the complex nature of innovation ecosystems as structures for value co-creation through new knowledge creation. Hence, based on two empirical case examples, this study offers important new insight into the co-existence of different value co-creation practices in

\section{Case A}

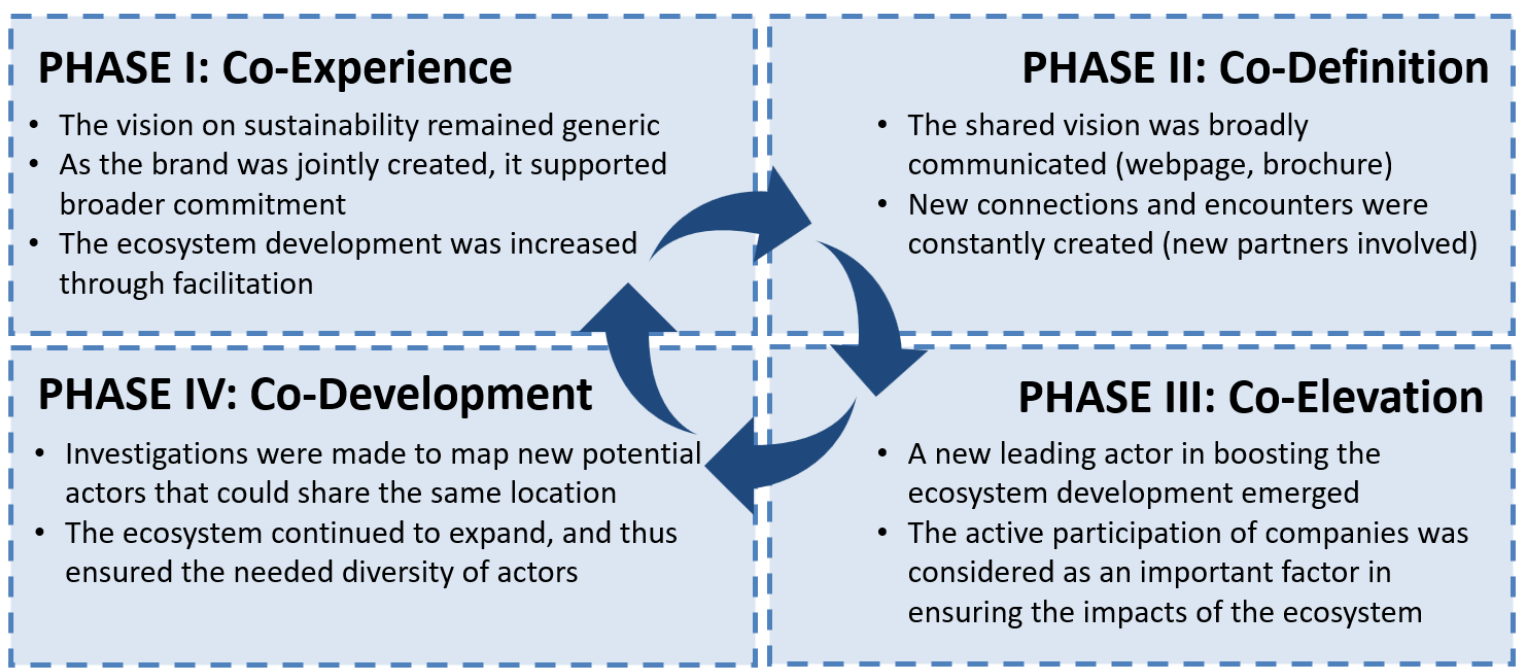

Figure 2. Practices enhancing value co-creation in case A

\section{Case B}

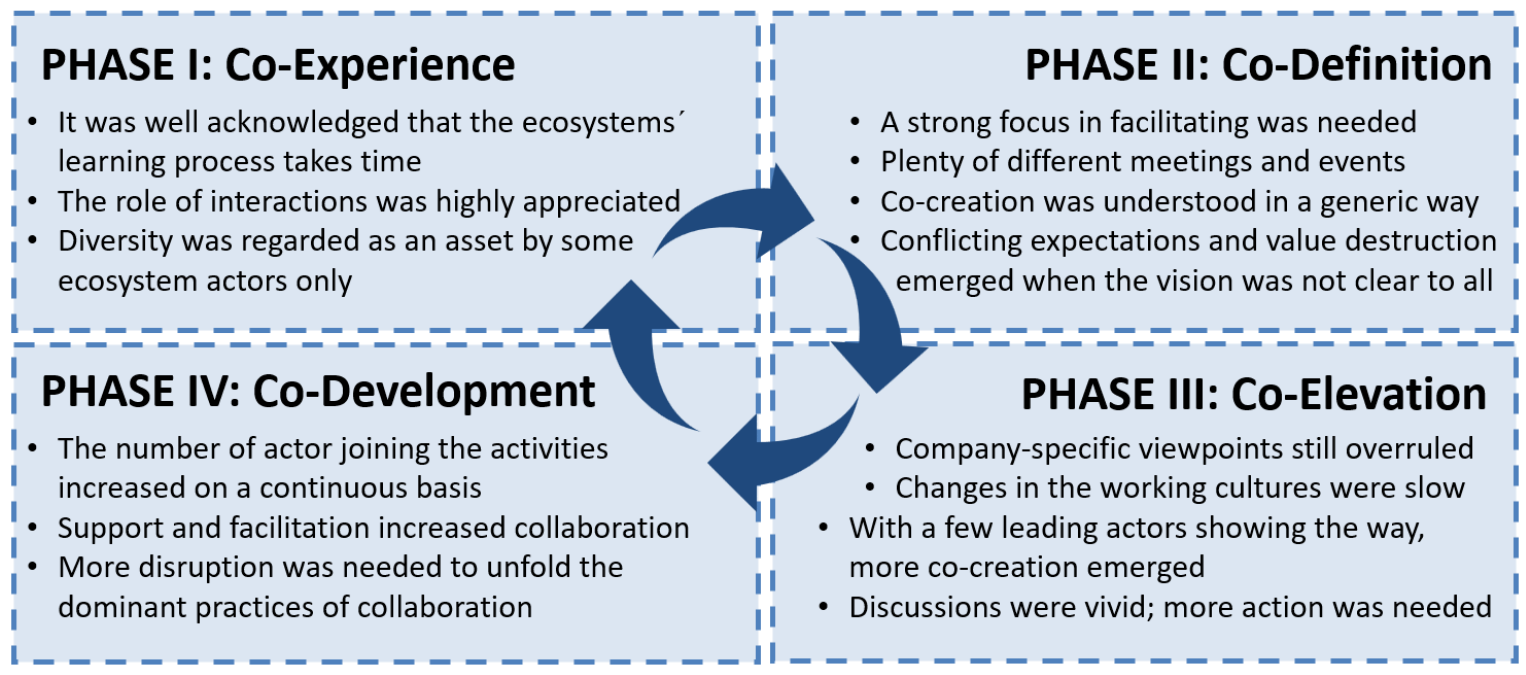

Figure 3. Practices enhancing value co-creation in case B 


\section{Innovation Ecosystems as Structures for Value Co-Creation}

\section{Sanna Ketonen-Oksi and Katri Valkokari}

the studied innovation ecosystems. In doing so, both theoretical and empirical understanding is provided regarding the value co-creation practices.

The results of this study are well in line with the twopart model approach to value co-creation (Kijima \& Arai, 2015). First, the importance of understanding the differences between platforms and ecosystems was highlighted. In doing so, in both cases, the platforms were identified as important venues for the ecosystem actors to get introduced to one another and to share their ideas for collaboration. Second, the different phases of value co-creation were observed, including the forms of interactions between the ecosystem actors. According to these observations, the process of value co-creation took place in several sub-systems (i.e., in various independent development projects and programmes occurring at the innovation ecosystem). This is highly in accordance with the recent understanding of ecosystems as the contexts at which the continuous interplay between multiple actors and with a number of overlapping purposes and different views emerges (Meynhardt et al., 2016; Valkokari, 2015). In addition, this study complements the earlier perspective on ecosystems-as-structures (Adner, 2017) by introducing two practical case examples where the emergence of coevolution dynamics is used to create new knowledge within the innovation ecosystems.

In both cases, the ecosystem development was somewhat hindered by the rather generic aims of collaboration and the conflicting expectations regarding the ecosystem development. For this reason, attention was given to the role of facilitators as important connectors or enablers of value co-creation. Surprisingly, despite the increasingly global nature of their activities, both ecosystems were largely dependent on having a concrete physical platform as the "home base" for the value co-creating activities. That is, a place where different people and organizations can meet and create trustbuilding collaborative ties. In case A, the shared use of a research laboratory and other facilities for research were provided for this. In case B, many events and meetings were organized for researchers and company representatives with common interests to meet.

Finally, as presented in Figure 4, in order to enhance the ecosystems' value co-creating potential in practice, it is highly essential to invest in two key principles. First, in order to ensure a certain diversity among the ecosystem actors, and to encourage them to actively participate in the platform, seek shared values and invest time and energy into making a clear vision that is easy to identify with. Second, support the vision with structures and facilitation that help to match people and ideas in concrete ways.

It is also noted that certain ecosystem actors - or at least their current business models - may fall by the wayside during the evolution of the innovation ecosystem towards several future business ecosystems. This means that participating in and facilitating collaborative innovation in ecosystems calls for a new kind of agility that, in some cases, requires companies to be willing to even kill their current business model(s) to survive within the evolving ecosystem. These aspects of systemic change

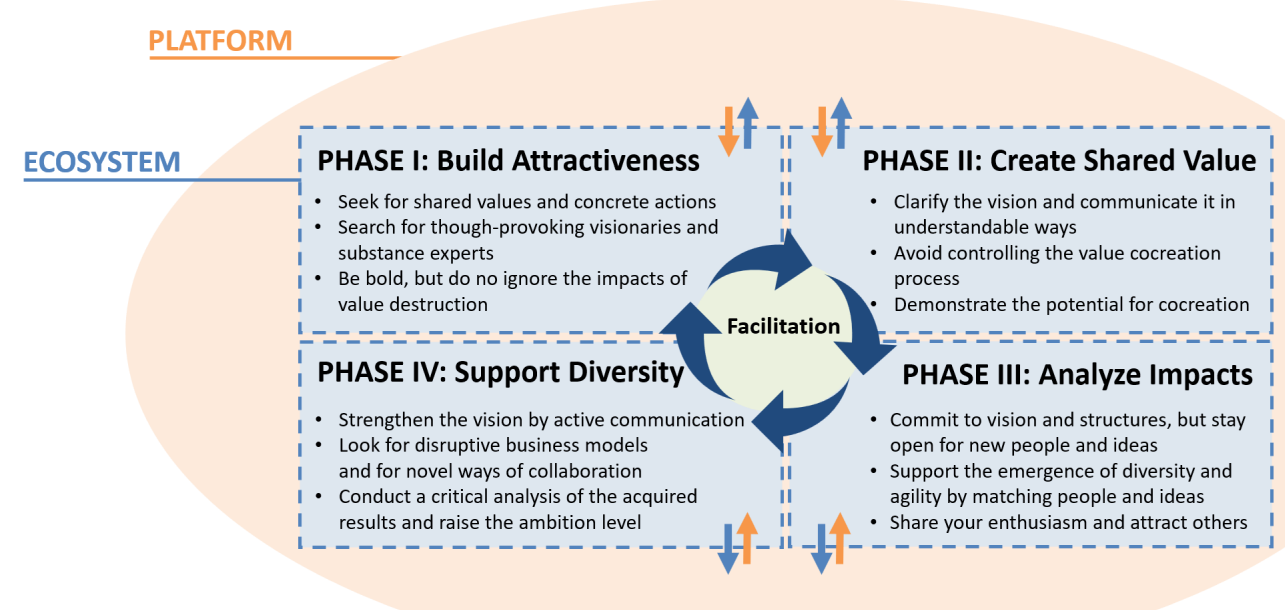

Figure 4. Summary of practices enhancing value co-creation in the studied innovation ecosystems 


\section{Innovation Ecosystems as Structures for Value Co-Creation}

\section{Sanna Ketonen-Oksi and Katri Valkokari}

are yet not sufficiently discussed by researchers or practitioners interested in value co-creation and collaborative innovation. As the complexity and multiplicity of actors participating in these innovation ecosystems increases, a more dynamic and open dialogue is required from all ecosystem actors to better understand and balance the interplay between value co-creation and value co-destruction.

\section{About the Authors}

Sanna Ketonen-Oksi works as a futurist-in-residence at Talent Vectia Oy (Espoo, Finland), a company offering strategic consulting and training services for organizations interested in renewal and new growth. With broad experience in EU-funded research, development, and innovation projects, often in university-industry collaboration, and based on her $\mathrm{PhD}$ studies on the service-dominant logical view on value co-creation and innovation, she sees that more understanding about innovation as a process of multi-actor collaboration is still needed. The growing complexity and dynamism of the innovation ecosystems is also an integral part of developing organizational futures orientation.

Katri Valkokari is a Research Manager working in the business, innovation, and foresight research area at VTT Technical Research Centre of Finland. She has over 15 years of experience in both research and practical development work on business networks, ecosystems, and networked business operations. She has, for example, held the post of programme manager in the large FIMECC (GP4V) and DIMECC (REBUS) research programmes, and worked for many industry companies, large and small. Katri has published several articles, managerial guidebooks and other publications related to collaboration models, innovation, and knowledge management as well as sustainability. When it comes to ecosystems and networks, Valkokari believes versatility is the key to creating true impact. When networks are formed openly, they can be a powerful tool for solving many of society's problems.

Citation: Ketonen-Oksi, S., \& Valkokari, K. 2019. Innovation Ecosystems as Structures for Value CoCreation. Technology Innovation Management Review, 9(2): 25-35. http://doi.org/10.22215/timreview/1216

Keywords: ecosystems, innovation, value co-creation, platforms

timreview.ca

\section{References}

Aarikka-Stenroos, L., \& Ritala, P. 2017. Network Management in the Era of Ecosystems: Systematic Review and Management Framework. Industrial Marketing Management, 67: 23-36. http://doi.org/10.1016/j.indmarman.2017.08.010

Akaka, M. A., Vargo, S. L., \& Wieland, H. 2017. Extending the Context of Innovation: The Co-Creation and Institutionalization of Technology and Markets. In T. Russo-Spena, C. Mele, \& M. Nuutinen (Eds.), Innovating in Practice: 43-57. New York: Springer International Publishing.

http://doi.org/10.1007/978-3-319-43380-6

Adner, R. 2016. Ecosystem as Structure: An Actionable Construct for Strategy. Journal of Management, 43(1): 39-58. http://doi.org/10.1177/0149206316678451

Autio, E., \& Thomas, L. D. W. 2014. Innovation Ecosystems: Implications for Innovation Management. In M. Dodgson, D. M. Gann, \& N. Phillips (Eds.), Oxford Handbook of Innovation Management: 204-228. Oxford: Oxford University Press. http://dx.doi.org/10.1093/oxfordhb/9780199694945.013.012

Barile, S., Lusch, R., Reynoso, J., Saviano, M., \& Spohrer, J. 2016. Systems, Networks, and Ecosystems in Service Research. Journal of Service Management, 27(4): 619-651.

https://doi.org/10.1108/JOSM-09-2015-0268

Clarysse, B., Wright, M., \& Bruneel, J. 2014. Creating Value in Ecosystems: Crossing the Chasm between, Knowledge and Business Ecosystems. Research Policy, 43(7): 1164-1176. http://dx.doi.org/10.1016/j.respol.2014.04.014

Dattée, B., Alexy, O., \& Autio, E. 2017. Maneuvering in Poor Visibility: How Firms Play the Ecosystem Game When Uncertainty Is High. Academy of Management Journal, 61(2): 466-498. https://doi.org/10.5465/amj.2015.0869

Edvardsson, B., Tronvoll, B., \& Gruber, T. 2011. Expanding Understanding of Service Exchange and Value Co-Creation: A Social Construction Approach. Journal of the Academy of Marketing Science, 39(2): 327-339.

https://doi.org/10.1007/s11747-010-0200-y

Eisenhardt, K. M. 1989. Building Theories from Case Study Research. Academy of Management Review, 14(4): 532-550.

https://doi.org/10.5465/amr.1989.4308385

Engel, J. S., \& Del-Palacio, I. 2011. Global Clusters of Innovation: The Case of Israel and Silicon Valley. California Management Review, 53(2): 27-49.

http://dx.doi.org/10.1525/cmr.2011.53.2.27

Galbrun, J., \& Kijima, K. 2009. Co-Evolutionary Perspective in Medical Technology: Clinical Innovation Systems in Europe and in Japan. Asian Journal of Technology Innovation, 17(2): 195-216. https://doi.org/10.1080/19761597.2009.9668679

Heikkula, A., Kowalkowski, C., \& Tronvall, B. 2018. Archetypes of Service Innovation: Implications for Value Cocreation. Journal of Service Research, 21(3): 284-301. https://doi.org/10.1177/1094670517746776

Järvi, K., \& Kortelainen, S. 2017. Taking Stock of Empirical Research on Business Ecosystems: A Literature Review. International Journal of Business and Systems Research, 11(3): 215-228. https://doi.org/10.1504/IJBSR.2017.085469 


\section{Innovation Ecosystems as Structures for Value Co-Creation}

\section{Sanna Ketonen-Oksi and Katri Valkokari}

Järvi, K., \& Almpanopoulou, A. 2018. Organization of Knowledge Ecosystems: Prefigurative and Partial Forms. Research Policy, 47(8): 1523-1537.

http://doi.org/10.1016/j.respol.2018.05.007

Kartemo, V., Kowalkowski, C., \& Edvarsson, B. 2018. Enhancing the Understanding of Process and Outcomes of Innovation - The Contribution of Effectuation to S-D Logic. In R. F. Lusch \& S. L. Vargo (Eds.), SAGE Handbook of Service-Dominant Logic: 522-535. London: SAGE.

Kijima, K., \& Arai, Y. 2016. Value Co-Creation Process and Value Orchestration Platform. In Kwan, S., Spohrer, J., \& Sawatani, Y. (Eds.), Global Perspectives on Service Science: Japan: 137-154. New York: Springer.

Kijima, K., Rintamäki, T., \& Mitronen, L. 2014. Value Orchestration Platform: Model and Strategies. In Proceedings of the Annual Conference of Japan Society for Management Information: 13-16. https://doi.org/10.11497/jasmin.2014f.0_13

Knyazev, G. G., Savostyanov, A. N., Bocharov, A. V., \& Merkulova, E. A. 2018. Resting State Connectivity Mediates the Relationship Between Collectivism and Social Cognition. International Journal of Psychophysiology, 123: 17-24.

https://doi.org/10.1016/j.ijpsycho.2017.12.002

Koskela-Huotari, K., Edvardsson, B., Jonas, J. M., Sörhammar, D., \& Witell, L. 2016. Innovation in Service Ecosystems-Breaking, Making, and Maintaining Institutionalized Rules of Resource Integration. Journal of Business Research, 69(8): 2964-2971. https://doi.org/10.1016/j.jbusres.2016.02.029

Lintula, J., Tuunanen, T., \& Salo, M. 2017. Conceptualizing the Value Co-Destruction Process for Service Systems: Literature Review and Synthesis. In Proceedings of the 50th Hawaii International Conference on System Sciences (HICSS 2017): 1632-1641. http://doi.org/10.24251/HICSS.2017.197

Lee, S. M., Olson, D. L., \& Trimi, S. 2012. Co-Innovation: Convergenomics, Collaboration, and Co-Creation for Organizational Values. Management Decision, 50(5): 817-831. http://dx.doi.org/10.1108/00251741211227528

Lusch R. F., \& Nambisan, S. 2015. Service Innovation: A ServiceDominant Logic Perspective. MIS Quarterly, 39(1): 155-175.

Meynhardt, T., Chandler, J. D., \& Strathoff, P. 2016. Systemic Principles of Value Co-Creation: Synergetics of Value and Service Ecosystems. Journal of Business Research, 69(8): 2981-2989. http://doi.org/10.1016/j.jbusres.2016.02.031

Moore, J. F. 1993. Predators and Prey: A New Ecology of Competition. Harvard Business Review, 71(3): 75-86.

Pellikka, J., \& Ali-Vehmas, T. 2016. Managing Innovation Ecosystems to Create and Capture Value in ICT Industries. Technology Innovation Management Review, 6(10): 17-24. https://doi.org/10.22215/timreview/1024

Pera, R., Occhiocupo, N., \& Clarke, J. 2016. Motives and Resources for Value Co-Creation in a Multi-Stakeholder Ecosystem: A Managerial Perspective. Journal of Business Research, 69(10): 4033-4041. http://doi.org/10.1016/j.jbusres.2016.03.047

Prahalad, C. K., \& Ramaswamy, V. 2004. Co-Creation Experiences: The Next Practice in Value Creation. Journal of Interactive Marketing, 18(3): 5-14.

https://doi.org/10.1002/dir.20015
Rajala, R., Gallouj, F., \& Toivonen, M. 2016. Introduction to the Special Issue on Multiactor Value Creation in Service Innovation: Collaborative Value Creation in Service. Service Science, 8(3): 249-357.

https://doi.org/10.1287/serv.2016.0157

Rohrbeck, R., Kum, M. E., Jissink T., \& Gordon, A. 2018. Corporate Foresight Benchmarking Report 2018: How Leading Firms Build a Superior Position in Markets of the Future. Aarhus, Denmark: Aarhus University.

https://dx.doi.org/10.2139/ssrn.3178562

Romero, D., \& Molina, A. 2011. Collaborative Networked Organisations and Customer Communities: Value Co-Creation and Co-Innovation in the Networking Era. Journal of Product Planning and Control, 22(4): 447-472. https://doi.org/10.1080/09537287.2010.536619

Schroth, F., \& Häußermann, J. J. 2018. Collaboration Strategies in Innovation Ecosystems: An Empirical Study of the German Microelectronics and Photonics Industries. Technology Innovation Management Review, 8(11): 4-12.

http://doi.org/10.22215/timreview/1195

Smorodinskaya, N., Russell, M. G., \& Katukov, D. 2017. Innovation Ecosystems vs. Innovation Systems in Terms of Collaboration and Co-creation of Value. Proceedings of the 50th Hawaii International Conference on System Sciences: 5245-5254. http://doi.org/10.24251/HICSS.2017.636

Spigel, B. 2017. The Relational Organization of Entrepreneurial Ecosystems. Entrepreneurship Theory and Practice, 41(1): 49-72. http://doi.org/10.1111/etap.12167

Stam, F. C., \& Spigel, B. 2016. Entrepreneurial Ecosystems. U.S.E Discussion Paper Series. Utrecht, The Netherlands: Utrecht School of Economics (U.S.E.), Utrecht University.

Suominen, A., Seppänen, M., \& Dedehayir, O. 2016. Innovation Systems and Ecosystems: A Review and Synthesis. In Proceedings of the 2016 ISPIM Innovation Conference, Porto, Portugal, June 19-22, 2016.

Valkokari, K. 2015. Business, Innovation, and Knowledge Ecosystems: How They Differ and How to Survive and Thrive within Them. Technology Innovation Management Review, 5(8): 17-24. https://doi.org/10.22215/timreview/919

Valkokari, K., Seppänen, M., Mäntylä, M., \& Jylhä-Ollila, S. 2017. Orchestrating Innovation Ecosystems: A Qualitative Analysis of Ecosystem Positioning Strategies. Technology Innovation Management Review, 7(3): 12-24. http://doi.org/10.22215/timreview/1061

Vargo, S. L., Maglio, P. P., \& Akaka, M. A. 2008. On Value and Value CoCreation: A Service Systems and Service Logic Perspective. European Management Journal, 26(3): 145-152. https://doi.org/10.1016/j.emj.2008.04.003

Vargo, S. L., \& Lusch, R. F. 2004. Evolving to a New Dominant Logic for Marketing. Journal of Marketing, 68(1): 1-17. https://doi.org/10.1509/jmkg.68.1.1.24036

Whalen, P. S., \& Akaka, M. A. 2016. A Dynamic Market Conceptualization for Entrepreneurial Marketing: The CoCreation of Opportunities. Journal of Strategic Marketing, 24(1): 61-75.

https://doi.org/10.1080/0965254X.2015.1035040 


\section{Academic Affiliations and Funding Acknowledgements}
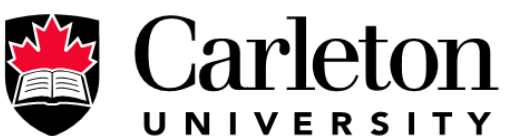

U N I V E R S I T Y

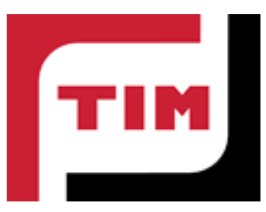

Technology Innovation Management (TIM; timprogram.ca) is an international master's level program at Carleton University in Ottawa, Canada. It leads to a Master of Applied Science (M.A.Sc.) degree, a Master of Engineering (M.Eng.) degree, or a Master of Entrepreneurship (M.Ent.) degree. The objective of this program is to train aspiring entrepreneurs on creating wealth at the early stages of company or opportunity lifecycles.

- The TIM Review is published in association with and receives partial funding from the TIM program. 